九州大学学術情報リポジトリ

Kyushu University Institutional Repository

\title{
Effects of Humidity on Development and Growth in the Tick, Haemaphysalis Longicornis
}

Yano, Yasuhiro

Zoological Laboratory, Faculty of Agriculture, Kyushu University

Shiraishi, Satoshi

Zoological Laboratory, Faculty of Agriculture, Kyushu University

Uchida, Teruaki

Zoological Laboratory, Faculty of Agriculture, Kyushu University

https://doi.org/10.5109/23873

出版情報 : 九州大学大学院農学研究院紀要. 32 (3/4)，pp.141-146，1988-03. Kyushu University バージョン：

権利関係 : 


\title{
Effects of Humidity on Development and Growth in the Tick, Haemaphysalis longicornis
}

\author{
Yasuhiro Yano, Satoshi Shiraishi* and Teru Aki Uchida \\ Zoological Laboratory, Faculty of Agricultre, \\ Kyushu University 46-06, Fukuoka 812
}

(Received A ugust 25, 1987)

\begin{abstract}
The cattle ticks in all developmental stages were reared at controlled humidities $(59.5,75.5$, 84.5 and $100 \% \mathrm{RH})$ and at a constant temperature of $30^{\circ} \mathrm{C}$. The hatch-ratio increased conspicuously as the humidities became high, but the average incubation period was merely slightly shortened. The larval moulting ratio at $100 \% \mathrm{RH}$ was very high compared with that at $84.5 \% \mathrm{RH}$; however, there was no significant difference in the average moulting period between both RH conditions. Every nymphal moulting ratio was generally high and the average moulting period at each humidity was almost constant. Only one of the three engorged females could oviposit at 59.5\% RH ; the number of the deposited eggs per mg of the body weight at $75.5 \% \mathrm{RH}$ and below did not reach the mean number for the body weight at $100 \% \mathrm{RH}$. The survival period of unfed ticks in each stage at $75.5 \% \mathrm{RH}$ and below was within two weeks, but as a whole, the survival periods were lengthened and the survival ratios heightened with increasing humidity. Thus, it is concluded that low humidities are more harmful to the earlier developmental stages and the lowest humidity for tick survival is between $84.5 \%$ and $75.5 \% \mathrm{RH}$, and that high humidities above $84.5 \% \mathrm{RH}$ are necessary to complete the life cycle.
\end{abstract}

\section{INTRODUCTION}

The humidity of the environment is of paramount importance in the life cycle of ticks. The critical equilibrium humidity at which the unfed ticks can maintain the body water balance by means of absorbing water vapor from the atmosphere is generally high, being between 70\% and 96\% RH (Kniille and Rudolph, 1982).

In Haemaphysalis longicornis, however, there has no determination of the lowest humidity for the survival of various stages, except for some occasional reports concerning the effects of humidity on hatching of the eggs (Namba, 1953 ; Heath, 1979), moulting of the engorged larvae (Heath, 1981) and oviposition (Fujisaki et al., 1975). As a basis for the control of $H$. longicornis, the most dominant tick on Japanese pasture, we examined the life cycle in the laboratory (Yano et al., 1985) and the effects of temperature on the development and growth (Yano et 'al., 1987). The purpose of the present study was to elucidate the effects of humidity on the development and the survival of the tick in all developmental stages, and to estimate the lowest humidity for the development and survival.

* To whom reprint requests should be addressed. 


\section{MATERIALS AND METHODS}

The ticks, H. longicornis (the bisexual strain) were collected by the flagging method on a pasture at Kujū Highland, Öita Prefecture, in mid-June 1985 and 1986. The eggs were taken from the egg masses laid by three engorged females in the laboratory. The unfed larvae, nymphs and females were fed to engorgement on the rabbits. The unfed larvae, which hatched under laboratory conditions and became active five days after hatching, and unfed nymphs as well as adults $(\circlearrowleft$, 古), both of which were captured on the pasture, were used for survival experiments.

The eggs and the ticks in various developmental stages (the unfed larva, engorged larva, unfed nymph, engorged nymph, unfed male and female, and engorged female) were put into plastic cases $(3 \times 6 \times 1.5 \mathrm{~cm})$ or glass tubes $(\mathrm{ht} .4 \mathrm{~cm}$, dia. $1.5 \mathrm{~cm})$ which were covered up by gauze and placed in desiccators with four different humidities as follows : $59.5 \% \mathrm{RH}\left(\mathrm{NH}_{4} \mathrm{NO}_{3}\right), 75.5 \% \mathrm{RH}(\mathrm{NaCl})$ and $84.5 \% \mathrm{RH}(\mathrm{KCl})$; each humidity was maintained by using about $300 \mathrm{ml}$ of the saturated solutions (Winston and Bates, 1960 ), and $100 \%$ RH was kept by putting a filter paper soaked continuously with water into the above cases and glass tubes. All humidities were checked twice a month by a hygrometer $( \pm 3 \%)$. The desiccators were placed in an incubator kept at a constant temperature of $30^{\circ} \mathrm{C}$. The eggs were left in the desiccators to hatch, and the ticks to moult and oviposit and then to be determined survival. The number of the eggs and the ticks used in the experiments are summarized in the tables.

\section{RESULTS}

\section{1. $H$ atching of the eggs (Table 1)}

The eggs hatched at $75.5 \% \mathrm{RH}$ and above ; the hatch-ratio conspicuously increased from 1.0 to $97.0 \%$ with rising humidity. The average incubation period, however, merely slightly shortened from 22.3 to 17.3 days.

\section{Moulting of the engorged larvae and nymphs (Table 2)}

The engorged larvae did not moult at the low humidities $(59.5 \%$ and $75.5 \% \mathrm{RH})$ and the moulting ratio at $100 \% \mathrm{RH}(88.0 \%)$ was very high compared with that at $84.5 \% \mathrm{RH}(27.3 \%)$; however, the average moulting period did not differ significantly between both the RH conditions (12.2 days at $84.5 \% \mathrm{RH}$ and 11.4 days at $100 \% \mathrm{RH}$ ).

Table 1. Egg hatchability at constant relative humidities and $30^{\circ} \mathrm{C}$ in Haemaphysalis longicornis.

\begin{tabular}{ccccc}
\hline \multirow{2}{*}{$\begin{array}{c}\text { Relative humidity } \\
(\%)\end{array}$} & $\mathrm{N}$ & $\begin{array}{c}\text { Hatch-ratio } \\
(\%)\end{array}$ & \multicolumn{2}{c}{$\begin{array}{c}\text { Incubation period } \\
\text { (days) }\end{array}$} \\
\cline { 3 - 4 } & & & average & range \\
\hline 59.5 & 300 & 0 & - & - \\
75.5 & 300 & 1.0 & 22.3 & $22-23$ \\
84.5 & 300 & 38.0 & 1.0 & $20-23$ \\
100 & 300 & 97.0 & $15-23$ \\
\hline
\end{tabular}


On the other hand, the engorged nymphs moulted at all humidities, every moulting ratio was high $(85.7-100 \%)$ and the average moulting period at each humidity was almost constant (10.2-11.7 days).

Table 2. Moulting of engorged larvae and nymphs at constant relative humidities and $30^{\circ} \mathrm{C}$ in Haemaphysalis longicornis.

\begin{tabular}{|c|c|c|c|c|c|c|c|c|}
\hline \multirow{3}{*}{$\begin{array}{c}\text { Relative } \\
\text { humidity } \\
(\%)\end{array}$} & \multicolumn{4}{|c|}{ Larval moulting } & \multicolumn{4}{|c|}{ Nymphal moulting } \\
\hline & \multirow[t]{2}{*}{$\mathrm{N}$} & \multirow{2}{*}{$\begin{array}{c}\text { Ratio } \\
(\%)\end{array}$} & \multicolumn{2}{|c|}{$\begin{array}{r}\text { Period } \\
\text { (days) }\end{array}$} & \multirow[t]{2}{*}{$\mathrm{N}$} & \multirow{2}{*}{$\begin{array}{c}\text { Ratio } \\
(\%)\end{array}$} & \multicolumn{2}{|c|}{$\begin{array}{r}\text { Period } \\
\text { (days) }\end{array}$} \\
\hline & & & average & range & & & average & range \\
\hline 59.5 & 22 & 0 & - & & 7 & 85.7 & 11.7 & $10-13$ \\
\hline 75.5 & 22 & 0 & & - & 10 & 100.0 & 11.0 & $10-13$ \\
\hline 84.5 & 22 & 27.3 & 12.2 & $10-16$ & 10 & 90.0 & 11.1 & $10-16$ \\
\hline 100 & 25 & 88.0 & 11.4 & $8-18$ & 25 & 92.0 & 10.2 & $9-12$ \\
\hline
\end{tabular}

Table 3. Oviposition at constant relative humidities and $30^{\circ} \mathrm{C}$ in Haemaphysalis longicomis.

\begin{tabular}{|c|c|c|c|c|c|c|c|c|c|}
\hline \multirow{2}{*}{$\begin{array}{c}\begin{array}{c}\text { Relative } \\
\text { humidity } \\
(\%)\end{array} \\
59.5\end{array}$} & \multicolumn{3}{|c|}{$\begin{array}{l}\text { Preoviposition } \\
\text { period in days } \\
\quad \text { (average) }\end{array}$} & \multicolumn{3}{|c|}{$\begin{array}{l}\text { Oviposition } \\
\text { period } \\
\text { in days } \\
\text { (average) }\end{array}$} & \multicolumn{3}{|c|}{$\begin{array}{l}\text { Number of eggs } \\
\text { deposited per } \\
\text { mg body weight } \\
\text { (average) }\end{array}$} \\
\hline & 4 & $\overline{5}$ & - & 8 & $\overline{14}$ & - & 7.7 & - & - \\
\hline 75.5 & 4 & $(5.0)$ & 6 & 10 & $(14.0)$ & 18 & 6.8 & 7.6 & 8.6 \\
\hline 84.5 & 4 & $\begin{array}{c}4 \\
(4.3)\end{array}$ & 5 & 9 & $\begin{array}{c}14 \\
(13.7)\end{array}$ & 18 & 9.4 & $\begin{array}{r}(7.7) \\
9.6\end{array}$ & 11.6 \\
\hline 100 & 4 & $\begin{array}{c}5 \\
(4.7)\end{array}$ & 5 & 18 & $\begin{array}{c}19 \\
(19.0)\end{array}$ & 20 & 11.1 & $\begin{array}{c}(10.2) \\
11.8 \\
(11.6)\end{array}$ & 11.8 \\
\hline
\end{tabular}

The number of the engorged females used at each humidity is three.

\section{Oviposition (Table 3)}

The engorged females deposited eggs at all humidities after almost constant preoviposition periods (4-6 days), except for two of the three females at 59.5\% RH. The average oviposition period was prolonged at high humidities (from 8 to 19.0 days) ; the number of the deposited eggs per $\mathrm{mg}$ of the body weight became heightened (from 7.7 to 11.6$)$ with increasing humidity.

\section{Survivability of the unfed ticks (Table 4, Fig. 1)}

The survival periods at $84.5 \% \mathrm{RH}$ and higher humidities were significantly longer than those at $75.5 \% \mathrm{RH}$ and below ; at $75.5 \% \mathrm{RH}$ and below all ticks died within 14 days. At the same humidity, there was no significant difference in the survival period between larvae and nymphs, while a conspicuous disparity was noted between the above two and the adult which lived for a long period (Table 4). 
Concerning the pattern of the survival curve in each stage, the survival ratio of the unfed ticks in the various developmental stages (the larva, nymph and adult) increased with rising humidity, and decreased rapidly and in a straight line at $75.5 \% \mathrm{RH}$ and below, but at $84.5 \% \mathrm{RH}$ and above it nearly remained at a plateau for a different period according to the stage, subsequently was lowered gradually (Fig. 1). Since the survivability of the adult did not differ between both sexes, the data were dealt with en bloc.

Table 4. Survival of unfed larvae, nymphs and adults at constant relative humidities and $30^{\circ} \mathrm{C}$ in Haemaphysalis longicornis.

\begin{tabular}{|c|c|c|c|c|c|c|c|c|c|}
\hline \multirow{3}{*}{$\begin{array}{c}\text { Relative } \\
\text { humidity } \\
(\%)\end{array}$} & \multicolumn{9}{|c|}{ Survival period (days) } \\
\hline & \multicolumn{3}{|c|}{ Larvae } & \multicolumn{3}{|c|}{ Nymphs } & \multicolumn{3}{|c|}{ Adults } \\
\hline & $\mathrm{N}$ & $\begin{array}{l}\text { aver- } \\
\text { age }\end{array}$ & range & $\mathrm{N}$ & $\begin{array}{l}\text { aver- } \\
\text { age }\end{array}$ & range & $\mathrm{N}$ & $\begin{array}{l}\text { aver- } \\
\text { age }\end{array}$ & range \\
\hline 59.5 & 66 & 1.9 & $1-3$ & 20 & 2.1 & $1-4$ & 20 & 2.7 & $1-5$ \\
\hline 75.5 & 100 & 2.7 & $1-5$ & 20 & 3.8 & $1-7$ & 20 & 8.8 & $1-14$ \\
\hline 84.5 & 68 & 24.8 & $1-40$ & 21 & 23.8 & $4-41$ & 20 & 53.4 & 2-107 \\
\hline 100 & 59 & 56.7 & $28-70$ & 50 & 59.0 & $26-94$ & 48 & 144.9 & $30-242$ \\
\hline
\end{tabular}

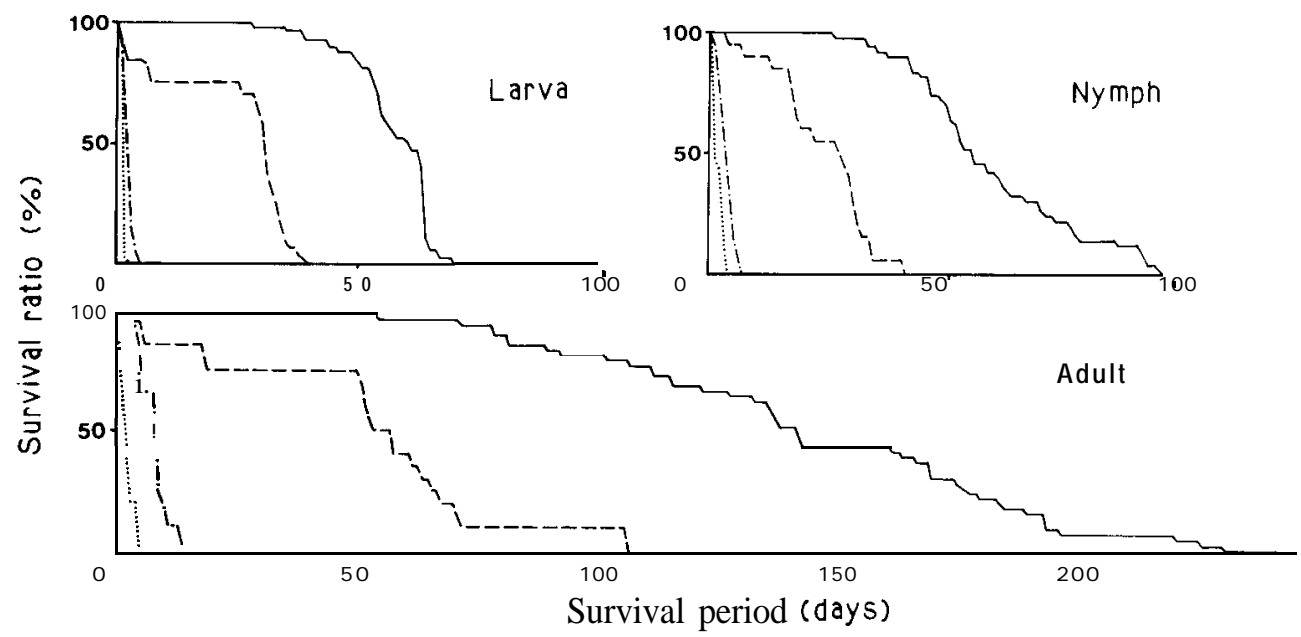

Fig. 1. Survivability curves of unfed larvae, nymphs and adults at constant relative humidities and $30^{\circ} \mathrm{C}$ in Haemaphysalis longicomis. -.-., 59.5\% RH ;-・-, 75.5\% RH ; ,$--- 84.5 \% \mathrm{RH} ;-, 100 \% \mathrm{RH}$

\section{DISCUSSION}

The drought resistance in $H$. longicornis varied with the developmental stages. The low humidities were harmful especially to the earlier developmental stages. The 
high ratios of hatching and larval moulting obtained at $100 \%$ RH were not achieved even at $84.5 \% \mathrm{RH}$ (Tables 1 and 2). Since the number of the deposited eggs failed to reach the normal number corresponding to the body weight of the engorged tick at $75.5 \% \mathrm{RH}$ and below (Table 3), the egg productivity also seems to be influenced by the low humidities. The humidities examined, however, had no effect on nymphal moulting, whose ratios were high even at the low humidities (Table 2). The survival periods were lengthened with increasing humidty, and the adult survived for a longer time than did the larva and nymph (Table 4 and Fig. 1).

The drought resistance in ticks varies also with the species, i. e. the lowest humidities for egg hatching are $75 \% \mathrm{RH}, 45 \% \mathrm{RH}, 60 \% \mathrm{RH}, 56 \% \mathrm{RH}$ and $33 \% \mathrm{RH}$ in Boophilus microplus (Hitchcock, 1955), Dermacentor variabilis and Amblyomma americanum (Sonenshine and Tigner, 1969), Boophilus decoloratus and Rhipicephalus evertsi (Rechav and Maltzahn, 1977), respectively ; oviposition takes place normally at $40 \%$ RH and above in B.microplus (Hitchcock, 1955 ; Bennett, 1974), at 45\% RH and above in D. variabilis and A. americanum (Sonenshine and Tigner, 1969) ; further, Rhipicephalus sanguineus (Sweatman, 1967) and Hyalomma aegyptium (Sweatman, 1968) can lay eggs even at $0 \% \mathrm{RH}$, and Hyalomma anatolicum (Snow and Arthur, 1966) at 25\% $\mathrm{RH}$.

Heath $(1979,1981)$ has reported the temperature and humidity suitability for egg hatching and larval moulting in the laboratory for three ticks (H. longicornis, Ixodes holocyclus, R. sanguineus) from Australia, and pointed out the correspondence between their temperature/humidity requirements and the climate within the geographic range of each species. R. sanguineus inhabiting the regions devoid of significant precipitation outside the wet season has the strongest drought resistance (hatching at 2-20 $\mathrm{mm} \mathrm{Hg}$ saturation deficit, moulting at $2-35 \mathrm{~mm} \mathrm{Hg} \mathrm{s}$. d. and a slow loss of water) ; on the contrary, I. holocyclus requires moderate temperatures and high moisture level for its survival and is poor in the drought resistance (unhatching at $4 \mathrm{~mm} \mathrm{Hg}$ s. d. and over, moulting at 2-4 mm $\mathrm{Hg}$ s. d. and a rapid loss of water). Thus, the differences in the drought resistance of tick species might well reflect their habitats and geographic distributions, and especially the humidity conditions required for egg hatching and larval moulting.

Unfed ticks must absorb moisture from the atmosphere for water maintenance until they attach to hosts. Ticks die within a given short period at less than the critical humidity (Knülle and Wharton, 1964). The critical equilibrium humidities of various kinds of tick species are summarized by Kntille and Rudolph (1982). Although in H. longicornis experiments on the changes of the body weight for various humidities were not attempted, judging from a great disparity in the survival period in each developmental stage between $75.5 \%$ and $84.5 \% \mathrm{RH}$, it is suggested that the critical equilibrium humidity for $\mathbf{H}$. Iongicornis is between them.

Nymphal moulting and oviposition occurred at $59.5 \% \mathrm{RH}$ in $\mathbf{H}$. Iongicornis, but both can take place at lower humidities, i. e. the former at 50\% RH (Morii and Kitaoka, 1971) and the latter at 53\% RH (Fujisaki, et al., 1975). Apart from this, it is concluded that the high humidities of $84.5 \% \mathrm{RH}$ and over are necessary for the completion of the life cycle in H. Iongicornis, although the lowest humidity for the development and survival varied with the stages. 


\section{ACKNOWLEDGEMENTS}

We thank the staffs of Kujū Agricultural Research Center, Kyushu University for facilities in collecting the ticks ; and Professor E. W. Jameson Jr., University of California for comments on the manuscript. This work was supported in part by a Grant-in-Aid from the Ministry of Education, Science and Culture, Japan.

\section{REFERENCES}

Bennett, G. F. 1974 Oviposition of Boophilus microplus (Canestrini) (Acarida : Ixodidae). II. Influence of temperature, humidity and light. Acarologia, $16: \mathbf{2 5 0 - 2 5 7}$

Fujisaki, K., S. Kitaoka and T. Morii 1975 Effect of different combinations of temperature and humidity on the oviposition of Haemaphysalis Iongicomis and Boophilus microplus. Bull. Nat. Inst. Anim. Hlth, 70: 27-34 (in Japanese)

Heath, A. C. G. 1979 The temperature and humidity preferences of Haemaphysalis Iongicornis, Zxodes holocyclus and Rhipicephalus sanguineus (Ixodidae) : Studies on eggs. Znt. J. Parasit., 9 : $33-39$

Heath, A. C. G. 1981 The temperature and humidity preferences of Haemaphysalis Iongicornis, Zxodes holocyclus and Rhipicephalus sanguineus (Ixodidae) : Studies on engorged larvae. Znt. $J$. Parasit., 11: 169-175

Hitchcock, L. F. 1955 Studies of the non-parasitic stages on the cattle tick, Boophilus microplus (Canestrini) (Acarina: Ixodidae). Aust. J.Zool., 3: 295-311

Kntille, W. and D. Rudolph 1982 Humidity relationships and water balance of ticks. In "Physiology of Ticks", ed. by F. D. Obenchain and R. Galun, Pergamon Press, Oxford/New York/Toront/ Sydney/Paris/Frankfurt, pp. 43-70

Kntille, W. and G. W. Wharton 1964 Equilibrium humidities in arthropods and their ecological significance. Proc. First Znt. Congr. Acarology, Acarologia, 6 : 299-306

Morii, T. and S. Kitaoka 1971 Resistance of eggs, larvae and nymphs for temperature in Haemaphysalis longicomzis. Proceeding of Suiyōkai, (20):14-15 (in Japanese)

Namba, N. 1953 On the effect of temperature and humidity upon the embrionic development of ticks in pasture. Res. Bull. Hokkaido Nat. Agric. Exp. Stn, (64) : 130-135 (in Japanese with English summary)

Rechav, Y. and H. C. Maltzahn 1977 Hatching and weight changes in eggs of two species of ticks in relation to saturation deficit. Ann. Ent. Soc. Am., 70 : 768-770

Snow, K. R. and D. R. Arthur 1966 Oviposition in Hyalomma anatolicum anatolicum (Koch, 1844) (Ixodoidea : Ixodidae). Parasitology, 56 : 555-568

Sonenshine, D. E. and J. A. Tigner 1969 Oviposition and hatching in two species of ticks in relation to moisture deficit. Ann. Ent. Soc. Am., 62 : 628-640

Sweatman, G. K. 1967 Physical and biological factors affecting the longevity and oviposition of engorged Rhipicephalus sanguineus female ticks. J. Parasit., $53: 432-445$

Sweatman, G. K. 1968 Temperature and humidity effects on the oviposition of Hyalommu aegyptium ticks of different engorgement weight. J. Med. Ent., $5: 429-439$

Winston, P. W. and D. H. Bates 1960 Saturated solutions for the control of humidity in biological research. Ecology, 41: 232-237

Yano, Y., S. Shiraishi and T, A. Uchida 1985 Fundamental studies on the control of the cattle tick, Haemaphysalis longicornis, at Kujū Highland. II. Development and growth of the tick under laboratory conditions. Sci. Bull. Fac. Agr., Kyushu Univ., 39 : 159-164 (in Japanese with English summary)

Yano, Y., S. Shiraishi and T. A. Uchida 1987 Effects of temperature on development and growth in the tick, Haemaphysalis Iongicomzis. Exp.Appl.Acarol., 3: 73-78 